\title{
MININMUM QUANTITY LUBRICATION IN DEEP HOLE DRILLING
}

\author{
Anand A Kulkarni ${ }^{1}$, Vinay Murgod ${ }^{2}$, Jayant Kittur ${ }^{3}$ \\ ${ }^{1}$ Lecturer, Department of Mechanical Engineering, KLS Gogte Institute of Technology, Udyambag Belgaum-590008, \\ Karnataka, India \\ ${ }^{2}$ Lecturer, Department of IP Engineering, KLS Gogte Institute of Technology, Udyambag Belgaum 590008, Karnataka, \\ India \\ ${ }^{3}$ Professor, Department of IP Engineering, KLS Gogte Institute of Technology, Udyambag Belgaum 590008, Karnataka, \\ India
}

\begin{abstract}
Tool wear being a natural phenomenon in all machining processes leads to tool failure. There is growing demand in machining process for high productivity with use of high cutting velocity and feed rate. Such machining inherently produces high cutting temperature. The performances of machining operations are changed by use metal cutting fluids because of their lubrication, cooling and chip flushing functions. Cooling lubrication is an essential condition to achieve the economical tool life and the required surface quality in many cases. Cutting fluids have both economic and technological aspects, but environmental concerns have become increasingly important to manufacturing processes Hence it is difficult to reach a total renouncement of the use of the cooling lubricants in metal cutting for environment reasons, while the minimization of cutting fluid will lead to economical benefits by way of saving lubricant costs and work piece/tool/machine cleaning cycle time. Against this background, the concept of Minimum Quantity Lubrication (MQL)or "near dry lubrication" act as an substitute to traditional fluids is an interesting means of addressing the issues of both economical and environmental intrusiveness, by combining the functionality of cooling lubrication and with extremely low consumption of cooling lubrication. Thus, this work proposes to explore the MQL, elimination of, or significant reduction in, cooling lubricants affects on long hole drilling components of a production system. To ensure an efficient process and successful implementation of Minimum Quantity Lubrication. A detailed analysis and adaptation of cutting parameters, cutting tools, machine tools and the production environment is conducted.
\end{abstract}

Keywords - High Productivity, Minimum quantity lubrication (MQL), environmental intrusiveness, alternative to traditional fluids, minimization of cutting fluid

$* * *$

\section{INTRODUCTION}

The conventional cutting fluids substances can seriously affect both health and environment These are used up in machining process and are considered a problem for manufacturers. Any Cutting fluids have both economic and technological aspects, but environmental concerns have become increasingly important to manufacturing processes Galvanized into action by pressure from environmental agencies, politicians have imposed ever stricter legislation to protect the environment and preserve energy resources. Industrial sector, research centres and universities have to put hand together to find alternative production processes, and create technologies that will minimize these residues which affect the environment. Presently metal working industry uses large quantities of water -based cooling fluids with high consumption and discard costs for machining which generates residue and impacting the environment. The increasing need for environmentally friendly production techniques and the rapid growth of cutting fluid disposal costs have justified the demand for an alternative to machining processes using fluids. However restricted use of cooling fluids and/or lubricants in metal-mechanical production processes industries as much as possible has been the goal of research in this field over the past decade. The concept of Minimum Quantity Lubricant (MQL) sometimes referred to as "near dry lubrication" [1] or "micro lubrication" [2],machining have become the focus of attention of researchers and technicians in the field of machining as an alternative to traditional fluids .There will be increased temperatures in these processes, reduction in tool life performance, loss of dimensional precision and geometry of the parts, and variation in the machine's thermal behavior if we drastic reduce or even complete elimination conventional fluids.

\subsection{Minimum Quantity Lubrication}

The latest technique to have been delivered in metal cutting fluid to the tool/work interface is MQL, also known as "Micro lubrication". Tool performance show substantial difference when a small quantity of fluid, when selected and applied properly, by using this technology. Cutting performance is the main basis while selecting flood coolant in conventional operations. While in MQL, secondary 
characteristics are important. These include their safety properties, (environment pollution and human contact), biodegradability, oxidation and storage stability .In MQL [4], lubrication is obtained via the lubricant, while a minimum cooling action is achieved by the pressurized air that reaches the tool/work interface. Further, MQL reduces induced thermal shock and helps to increase the work piece surface integrity in situations of high tool pressure. Basically MQL delivery systems are of two types: External minimal quantity lubrication (MQL) and Internal minimal quantity lubrication (MQL).

External minimal quantity lubrication (MQL) Fig 1. System consists of a coolant tank or reservoir which is connected with tubes fitted with one or more nozzles. The system can be assembled near or on the machine and has independently adjustable air and coolant flow for balancing coolant delivery. It is inexpensive, portable, and suited for almost all machining operations.

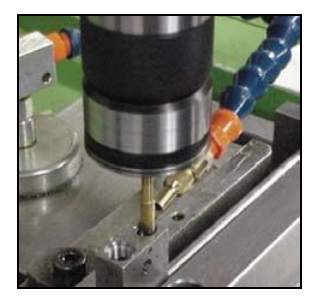

Fig1. Image of external MQL courtesy [3]

Internal minimal quantity lubrication (MQL) [5, 6] Fig 2. Systems here air-oil mist is created .The oil and pressurized air is mixed and fed on the job through the spindle near to the tool and the cutting zone interface

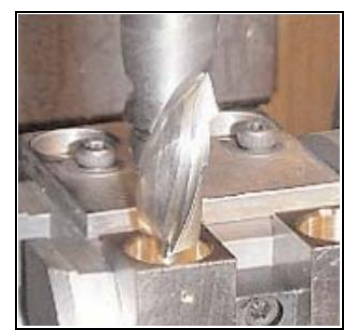

Fig 2 Image of Internal MQL.[3]

\subsection{Working Principle of MQL}

With minimal quantity lubrication the lubrication $\mathrm{b} / \mathrm{w}$ the tool and work piece is done with a flow of air containing finely dispersed droplets of oil called Aerosol. The system contains a special aerosol generator that can produce aerosols with an oil droplet size of $0.5 \mu \mathrm{m}$ Thanks to this small size the droplets of oil have hardly any inertia or rate of fall That makes it possible to transport the aerosol over long distances, via sharp deflections or high speed rotating tool spindles without any notable demixing, so all the lubricant particles are fed to the tool's cutting edge

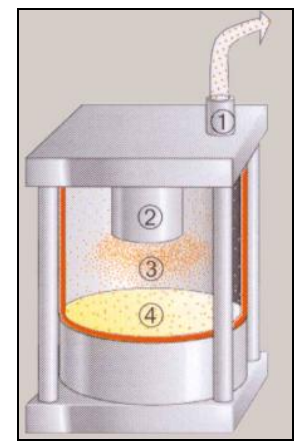

Fig 3 Image of Aerosol generator [3]

1) Aerosol Transport 2) Aerosol Generator 3) Lubricating particle 4) Lubricant.

\subsection{Aerosol Working}

The size and distribution of the droplets of oil in the aerosol are very homogenous with minimal quantity lubrication systems since the aerosol is atomized under controlled conditions. Those results in physical advantages: In addition to the high degree of surface wetting, extremely fine particles of lubricant also reach poorly accessible or hidden spots on the work piece. Difficult through feed tasks with deflections of the kind found in the turrets of turning machines can also be handled. Nor does the transport of aerosol to the active site present any problem in the case of milling machines running at speeds of more than $20,000 \mathrm{rpm}$. Lines as long as $20 \mathrm{~m}$ from the minimal quantity lubrication system to the machining site are likewise no problem for these installations either. The friction, and thus the transfer of heat from the chip to the work piece, is reduced. Optimal lubrication during removal of the chips in the chip groove not only permits higher machining speeds but also results in a much better work piece surface finish

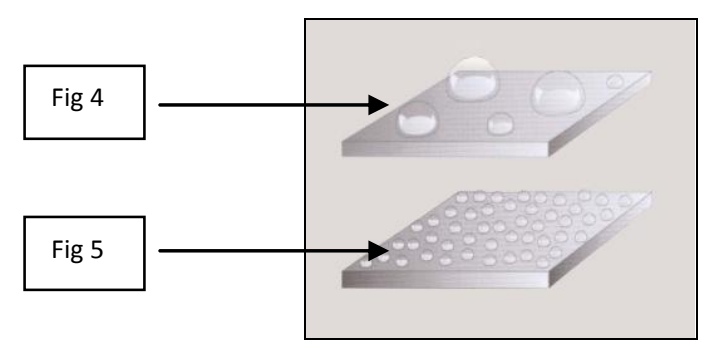

Fig 4 (conventional processes): Poor wetting of the work piece and tool due to uncontrolled atomization of the air/oil droplets at the nozzle.

Fig 5 MQL droplets wet the work piece evenly due to much smaller, homogenous droplets. Images Courtesy [3] 


\subsection{Working of Internal MQL}

A fine aerosol with an homogenous particle size of $\sim 0.5 \mu \mathrm{m}$ is produced in the reservoir from a lubricant and compressed air with a special nozzle system. Thanks to the small particle size, the aerosol passes through the rotating spindles of machining centres or through the winding ducts of turrets on modern turning centres without any demixing taking place en route. Dependable machining is assured by such loss free transport. Modern machining centres with a large number of tools require individual control of the aerosol quantity by stored program control (SPC) of the machine tools. This control possibility is provided by the Digital system. The aerosol quantity and composition required for the respective tool and cutting task are set by valves switched with $\mathrm{M}$ or $\mathrm{H}$ commands from the machine's control system. The required aerosol quality is adjusted with the Various system by manual regulation of the air pressure and quantity of lubricant.

\section{EXPERIMENTAL SET UP}

\subsection{Minimum Quantity Lubrication applied to Drilling Process}

The boreholes with a length-to-diameter ratio L/D > 3 are called Deep drill hole and gun drills are in this process. For small tool diameters $\mathrm{d}<12 \mathrm{~mm}$ two commonly used methods exist. Due to the asymmetric design of the single-lip drill and its single cutting edge the productivity of this method is limited. The use of solid carbide twist drills offers an alternative to the single-lip drilling and usually allows higher feed rates. The specification are mentioned in Table 1.This technique is generally utilised in operations for bore with slenderness ratio $\leq 40$. High heat flux is generated $b / w$ the interface of work piece and drill because of the relatively long machining time of deep hole drilling operations. Particularly in deep hole drilling operations, the MQL- concept is currently frequently introduced as it provides more ecological and economical substitute to the common emulsion coolant. At higher temperatures there is increase of the adhesion affinity and the lower chip breakage ability of the material with this reliability of the deep hole drilling process can be affected . Hence the knowledge of the heat generation and distribution is important for the reliable design of the MQL machining process, in particular the deep hole drilling using twist. The investigations were carried out on a multi-axis- machining centre. Additionally a MQL device with an operating pressure of $\mathrm{PMQL}=10$ bar was used in order to realize a reliable chip removal along the flutes of the twist drill. During machining use of pressure of Pair $=\mathrm{PMQL}=6$ bar with compressed air and MQL did not provide the needed lubrication and cooling performance. To overcome the above problem of continuous chip formation, jammed flutes and finally tool breakage a higher pressure of $p=12$ bar was used. The cutting speed of $\mathrm{Vc}=150 \mathrm{~m} / \mathrm{min}$ and $\mathrm{Vc}=220 \mathrm{~m} / \mathrm{min}$ as well as the feed of $f=0.15 \mathrm{~mm}$ and $\mathrm{f}=0.35 \mathrm{~mm}$. The cutting parameters such as the feed was varied between $f=0.15 \mathrm{~mm}$ and $\mathrm{f}=0.35$ $\mathrm{mm}$ by constant cutting speed of $\mathrm{Vc}=175 \mathrm{~m} / \mathrm{min}$ so as to build relation $b / w$ cutting speed, the feed and the heat input into the work piece. The solid carbide uncoated drill $\emptyset 12 X 300 \mathrm{~mm}$ as flute length were used .For calculating mechanical load the geometry of drill depth of $1=270 \mathrm{~mm}=27 \mathrm{xd}$, was used . Further- more, the twist drills feature a non-rounded cutting edge and polished flutes in order to achieve an enhanced chip breakage behaviour and friction-reduced chip removal. The pilot hole had the depth of $1 \mathrm{p}=35 \mathrm{~mm}$ and was generated by a stub drill, which has a diameter of $\mathrm{d}=12.030 \mathrm{~mm}$ and a included angle $\sigma=150^{\circ}$, in order to provide guidance and centering of the deep hole drill.

\subsection{Mechanical Load Analysis and Results}

The results of the mechanical load analysis are presented in Figure .Both the feed force Ff Fig. 6 and the drilling torque Md Fig. 8 demonstrate a nearly linear dependency on the feed and a minor correlation to the cutting speed. When the cutting speed was increased from $\mathrm{Vc}=150 \mathrm{~m} / \mathrm{min}$ to $\mathrm{Vc}=220 \mathrm{~m} / \mathrm{min}$ and experiments with a feed of $\mathrm{f}=0.15 \mathrm{~mm}$ then feed force increased by approximately 50\%. For small feed rates the friction at the chisel edge has a significant influence on the feed force due to the small undeformed chip thickness. When drilling with higher feed rates the cutting speed dependent effects become minor since the undeformed chip thickness at the major cutting edge as well as the effective rake angle increase. When the feed was increased from $\mathrm{f}=0.15 \mathrm{~mm}$ to $\mathrm{f}=$ $0.35 \mathrm{~mm}$ the feed force $\mathrm{Ff}$ and the drilling torque Md were approximately doubled .The analysis of the cutting forces has shown that the feed is the major influencing factor on the machining process.

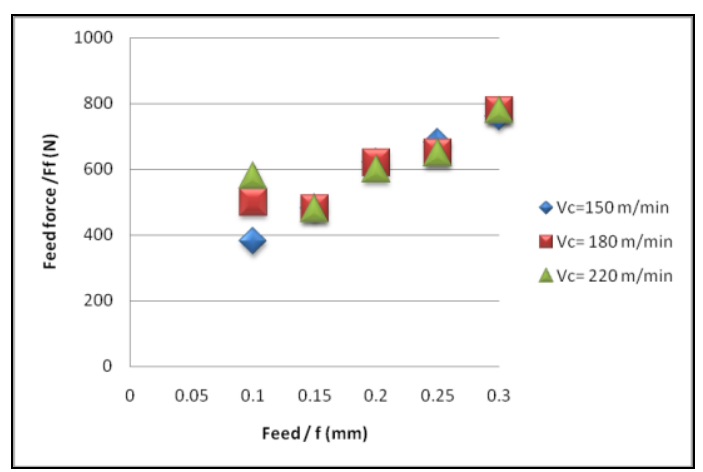

Fig 6 Variation of Feed force Ff (N) against Feed $\mathrm{f}(\mathrm{mm})$ for varied cutting speed 


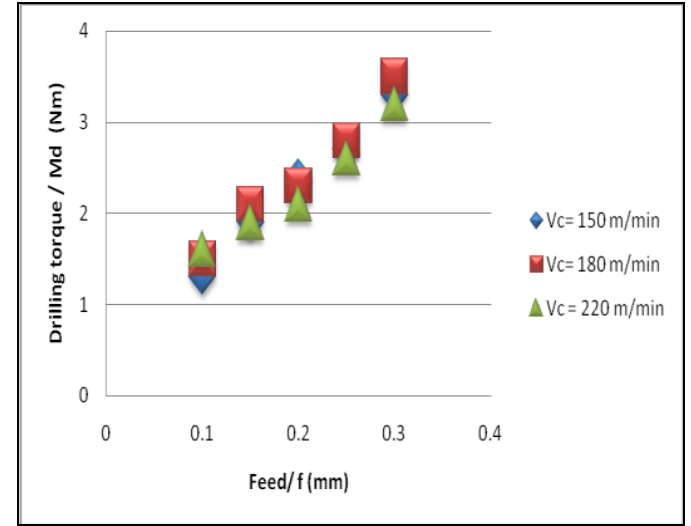

Fig. 7 Variation of Drilling torque $\mathrm{Md}(\mathrm{Nm})$ against Feed $\mathrm{f}$ $(\mathrm{mm})$ for varied cutting speed

Table 1 Experimental specifications

\begin{tabular}{|l|l|l|l|}
\hline Material & $\begin{array}{l}\text { Forged } \\
\text { steel }\end{array}$ & $\begin{array}{l}\text { Cutting } \\
\text { Material }\end{array}$ & $\begin{array}{l}\text { Solid carbide } \\
\text { drill }\end{array}$ \\
\hline Diameter & $\mathrm{D}=12 \mathrm{~mm}$ & Drilling Depth & $270 \mathrm{~mm}$ \\
\hline $\begin{array}{l}\text { L/D } \\
\text { Ratio }\end{array}$ & $\mathrm{L} / \mathrm{D}=25$ & Cutting speed & varied \\
\hline Feed & Varied & $\begin{array}{l}\text { Coolant } \\
\text { Pressure }\end{array}$ & P MQL $=12 \mathrm{bar}$ \\
\hline Coolant & MQL & Pilot hole depth & $35 \mathrm{~mm}$
\end{tabular}

Below are the optical images of the carbide drill which have been obtained from the Zoller tool pre setter Fig . 8 ,9 solid carbide after 80 holes in flooding conditions; Fig. 11,12 Same drill after 160 holes in H2O-MQL conditions

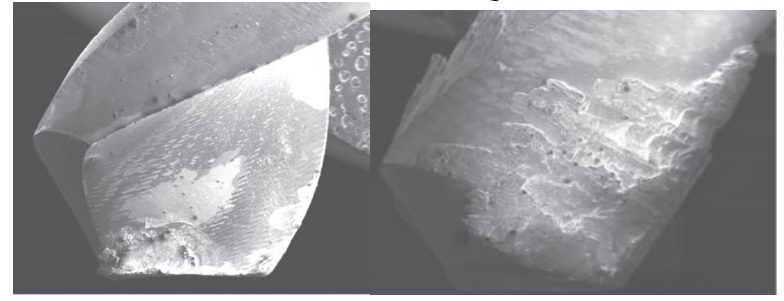

Fig .8, 9 carbide drill after 80 holes in flooding condition

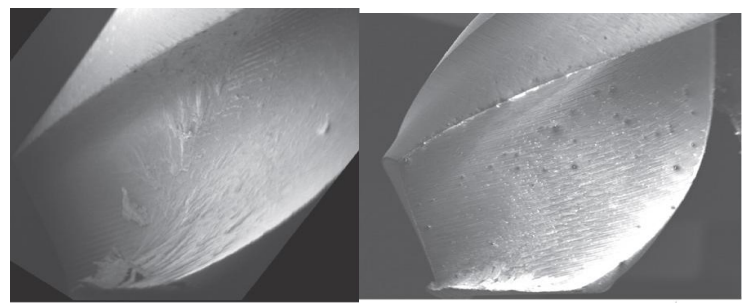

Fig. 10, 11 carbide drill after 160 holes in MQL condition
Also find the photos of the chip obtained in flooding condition and MQL condition Fig 12 are the chips in flooding condition and Fig. 13 under MQL condition

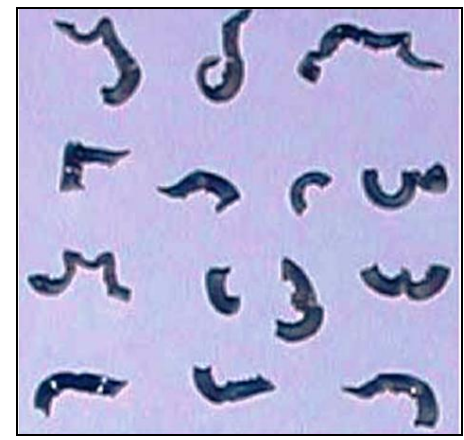

Fig 12 Chips obtained during flooding condition

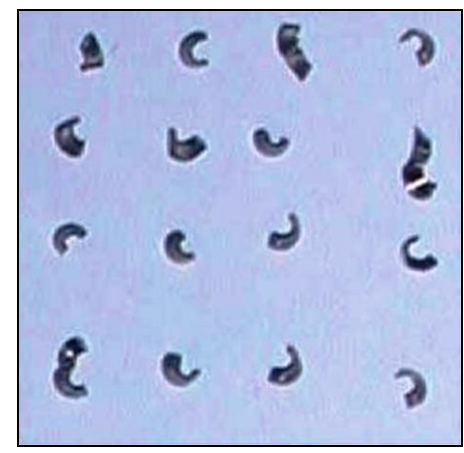

Fig 13 Chips obtained during MQL condition

\section{CONCLUSIONS}

An experimental study has been performed to examine the effect of minimum quantity lubrication over flooding condition in the long hole drilling The process attributes analysed herein have included the cutting forces and tool life. In the context of tool life, the study has shown a significant increase of tool life - over 30\% -- by minimum quantity lubrication over a wide range of cutting conditions. It can thus be concluded that the use of cutting fluid at minute amounts can potentially protect the tool while holding the cutting forces relatively unchanged in comparison to flooding cutting condition. Other machining performance issues in terms of chip flushing, temperature, surface finish and environmental consciousness have not been included in this study. Further research in these directions is suggested

\section{REFERENCES}

[1] Klocke, F., Eisenblatter, G., "Dry Cutting," Annals of the CIRP, 46 (2), pp. 519-526,1997

[2] MaClure, T.F.,Adams, R.and Gugger, M.D, Comparison of Flood vs Micro lubrication on Machining Performance, website: http://www.unist.com/techsolve.html,2001 
[3] www.vogel.com V000 06/2003

[4] L. Alden Kendall, Friction and wear of cutting tools and cutting tool materials, in: ASM Handbook, vol. 18, ASM International, The Materials Information Society, 1998, pp. 609-620, ISBN 0-87170-380-7.

[5] K. Weinert, I. Inasaki, J.W. Sutherland, T. Wakabayashi, Dry machin- ing and minimum quantity lubrication, Ann. CIRP 53 (2) (2004) pp 511-537.

[6] G. Byrne, D. Dornfeld, B. Denkena, Advancing cutting technology, Ann. CIRP 52 (2) (2003) pp 483-507. 